\title{
Artigos
}

\section{Uso de bebidas alcoólicas por estudantes: análise de propagandas de festas em um campus universitário}

\author{
Student drinking: an analysis of parties advertisements on an university \\ campus (abstract: p. 21)
}

\section{Uso de bebidas alcohólicas por parte de estudiantes: análisis de anuncios de fiestas en un campus universitario (resumen: p. 21)}

\author{
Emílio Martins Curcelli(a) \\ <emilio.curcelli@gmail.com> \\ Bruno José Barcellos Fontanella ${ }^{(b)}$ \\ <bruno@ufscar.br>
}

\author{
(a) Graduando do curso de Medicina, \\ Centro de Ciências Biológicas e da \\ Saúde (CCBS), Universidade Federal \\ de São Carlos (Ufscar). Rodovia \\ Washington Luís, km 235, SP-310. \\ São Carlos, SP, Brasil. 13565-905. \\ (b) Departamento de Medicina, CCBS, \\ Ufscar. São Carlos, SP, Brasil.
}

A proposta deste trabalho foi interpretar as imagens de propagandas de festas veiculadas em um campus universitário em relação ao consumo de álcool por estudantes. Os elementos plásticos, icônicos e linguísticos das propagandas foram submetidos a uma análise semiótica de imagens. Organizaram-se os 85 temas levantados em seis categorias: bebidas alcoólicas, sexualidade, gênero, produção das festas, estilos musicais e estilo de vida-grupos-comportamento. Foram veiculados diversas motivações festivas, atrações, questões de gênero, valores, tradições e finalidades econômicas. Menções a bebidas alcoólicas foram praticamente ubíquas. Os elementos persuasivos ao consumo de álcool foram variados, envolvendo a associação álcool-sexualidade e a apresentação de novos comportamentos e estilos de vida relacionados à bebida. A indústria de produção e comércio de bebidas parece inserir-se mercadologicamente no território do campus, de modo informal e quase sempre sem seguir a legislação de marketing desses produtos.

Palavras-chave: Bebidas alcoólicas. Saúde do estudante. Marketing. Festas estudantis. Propagandas. 


\section{Introdução}

O uso de substâncias psicoativas por estudantes universitários vem sendo estudado extensamente nas últimas duas décadas, no Brasil e no exterior. Mais frequentemente, são pesquisados seus aspectos epidemiológicos, procurando evidenciar a distribuição desse comportamento em relação a parâmetros sociodemográficos entre os adolescentes e adultos jovens no ensino superior. Menos reiterados são os estudos de questóes psicoculturais envolvidas no consumo.

Aspectos psicoculturais, nessa área, podem se referir a questôes típicas dessa fase do ciclo vital, como os conflitos da transição entre adolescência e fase adulta e ao processo de socialização que se opera durante a vida universitária, vulnerabilidades que podem predispor os indivíduos ao consumo prejudicial de substâncias psicoativas ${ }^{1,2} \cdot \mathrm{Na}$ presente investigação, o objeto de pesquisa situa-se na esfera do marketing informal ${ }^{3}$ : os papéis que materiais publicitários presentes em um campus podem ter no padrão de consumo de substâncias psicoativas, particularmente do álcool, pelos universitários.

A escolha deste objeto de pesquisa se deveu à extensa e contínua presença, nos campi universitários, de materiais publicitários referentes a eventos artísticos, de política estudantil, cursos extracurriculares, aulas particulares e, particularmente, de festas - sendo observável, mesmo em uma análise superficial, a presença de referências a bebidas alcoólicas em alguns desses materiais.

De elaboração geralmente não profissional, à primeira vista não parecem seguir as regulamentaçôes legais para o marketing de bebidas alcoólicas ${ }^{4}$. Presumimos também serem utilizados, nesses materiais, elementos que sugerem o uso de bebidas alcoólicas como um facilitador da socialização e do enfrentamento das dificuldades psicossociais próprias da vida universitária. Evocariam certos valores tidos como positivos, com possíveis consequências de induzir a determinadas atividades de lazer e hábitos, possivelmente interferindo na construção da identidade social dos estudantes.

Com esses pressupostos em mente, o objetivo geral da pesquisa foi interpretar os elementos plásticos, icônicos e linguísticos de imagens presentes em propagandas de eventos festivos, veiculadas em cartazes de distribuição e afixação em locais de frequentados por estudantes no campus de São Carlos da Universidade Federal de São Carlos (UFSCar), ao longo de um ano acadêmico. Especificamente, nossos objetivos foram compreender: a) os elementos simbólicos que comporiam o sistema de ideias e valores propagandeados; $b$ ) de que maneira as imagens se relacionariam ao processo de socialização dos estudantes, ou seja, à aquisição de novos papéis e ao ajustamento psicológico às perdas de papéis anteriores; e c) os elementos simbólicos associados às menções de bebidas alcoólicas, incluindo os elementos possivelmente persuasivos ao consumo.

Esses objetivos nos parecem justificáveis em face da constatação, nas últimas duas a três décadas, do uso persistentemente prevalente e intenso de álcool entre estudantes universitários $^{5}$. Sabe-se que esse uso pode se associar ao de outras substâncias ${ }^{6} \mathrm{e}$ eventualmente está associado a quadros psicopatológicos, embora geralmente não esteja ${ }^{7}$. Entretanto, tal consumo muito provavelmente se associa ao chamado "uso de risco", ou seja, a uma maior probabilidade de eventos como acidentes de trânsito, danos físicos à saúde, episódios de violência, sexo sem proteção, prejuízos acadêmicos, etc. $^{7-11}$. No Brasil, o uso de álcool entre universitários parece ser mais frequente entre os estudantes que referem sofrer algum tipo de discriminação social ${ }^{12}$, os que se 
declaram sem religião', com maiores rendimentos financeiros familiares e os do sexo masculino ${ }^{13-15}$.

Exposição à publicidade de bebidas alcoólicas parece também estar relacionada ao consumo feito por uma parcela dos jovens. Pesquisas realizadas no Brasil sobre propagandas de bebidas alcoólicas são relativamente pouco numerosas. Revisóes brasileiras sobre a literatura internacional ratificaram a hipótese de que conteúdos veiculados em mensagens publicitárias influenciam a tomada de decisóes sobre consumir álcool, sendo isso particularmente importante quanto ao início precoce de consumo e quanto ao consumo em grandes quantidades ${ }^{16,17}$. Não identificamos estudos longitudinais nacionais que ratifiquem em nosso meio essa relação de causalidade; entretanto, há estudos transversais que mostraram uma prevalência de consumo abusivo cerca de três vezes maior entre universitários que viram anúncios de bebidas ${ }^{18}$, assim como a existência de uma relação positiva entre três fenômenos vivenciados por estudantes do ensino médio: apreciar propagandas de bebidas, exporse mais frequentemente a essas propagandas e consumir em maiores quantidades ${ }^{16}$. Outras análises qualitativas de cartazes de festas expostos em campi universitários brasileiros já foram feitas e publicadas, tendo sido ressaltado pelas autoras o enaltecimento feito ao consumo de álcool a partir de diferentes tipos de recursos linguísticos e visuais presentes nesses cartazes ${ }^{19,20}$.

\section{Material e métodos}

Foi empregado o método semiótico para a análise de imagens organizado por Martine Joly ${ }^{21}$, desenvolvido em quatro fases: análise da mensagem plástica, considerando os recursos plásticos utilizados na confecção dos cartazes e imagens digitalizadas; análise da mensagem icônica, com os possíveis significados de primeiro nível e de segundo nível dos temas representados; análise da mensagem linguística, considerando os textos presentes nas imagens e seus conteúdos e funções linguísticas; e, por fim, a partir dessas três etapas iniciais, foram elaboradas sínteses gerais das mensagens implícitas em cada imagem. Tais sínteses corresponderam às associações ideativas feitas pelos pesquisadores, sendo produto, portanto, de seus conhecimentos e repertórios culturais, considerando suas próprias inserçóes sociais como aluno de graduação e professor, resultando em hipóteses sobre as significações das imagens. Dado o caráter polissêmico das imagens, as sínteses interpretativas dos pesquisadores revelaram apenas alguns dos aspectos das significaçôes possíveis.

\section{Coleta de material}

A coleta de dados foi realizada no campus de São Carlos da UFSCar. Esse é um dos quatro campi da Universidade Federal de São Carlos, situada no interior do estado de São Paulo, Brasil, com 33 cursos de graduação presenciais e setenta cursos de pósgraduação nas áreas de ciências da saúde, biológicas, humanas e exatas/tecnológicas. $\mathrm{O}$ campus de São Carlos é frequentado por cerca de 8500 alunos de graduação e 3300 alunos de pós-graduação stricto sensu.

Ao longo de 12 meses, foram fotografados todos os cartazes afixados ou distribuídos no campus e foram arquivadas as imagens digitalizadas. Foram excluídas aquelas que 
servem de anúncio a atividades oficiais da universidade (divulgação de congressos, palestras e atividades de extensão universitária).

Semanalmente, sete locais do campus de alta frequentação estudantil foram visitados: as cercanias do restaurante universitário e de cinco lanchonetes e um ponto de ônibus - locais tradicionais de distribuição e afixação de propagandas, sem tramitação e autorização oficiais por instâncias universitárias. Esse material resultou em um corpus fotográfico extenso, mantido em arquivos digitais, numerado por ordem cronológica do registro.

\section{Forma de análise}

Um formulário de caracterização e análise das imagens foi utilizado, compreendendo anotaçóes sobre o contexto de exposição da imagem no campus e sobre as possíveis mensagens associadas à imagem. No fim, para cada imagem foi realizada uma síntese geral de análise. Esses passos analíticos estão baseados no texto de Martine Joly, tendo como fundamentação conceitual básica os textos de semiótica geral $^{22-25}$.

Ao fim das análises individuais das imagens, o conjunto de sínteses gerais passou por um processo de categorização, ou seja, por uma tentativa de identificação, ordenamento e classificação das significações atribuídas ao material analisado pelos pesquisadores.

Como ilustração, reproduzimos seis imagens (cerca de $3 \%$ do corpus de imagens) a partir das quais inferimos alguns dos temas que compuseram as categorias temáticas (figuras de 1 a 6 ).

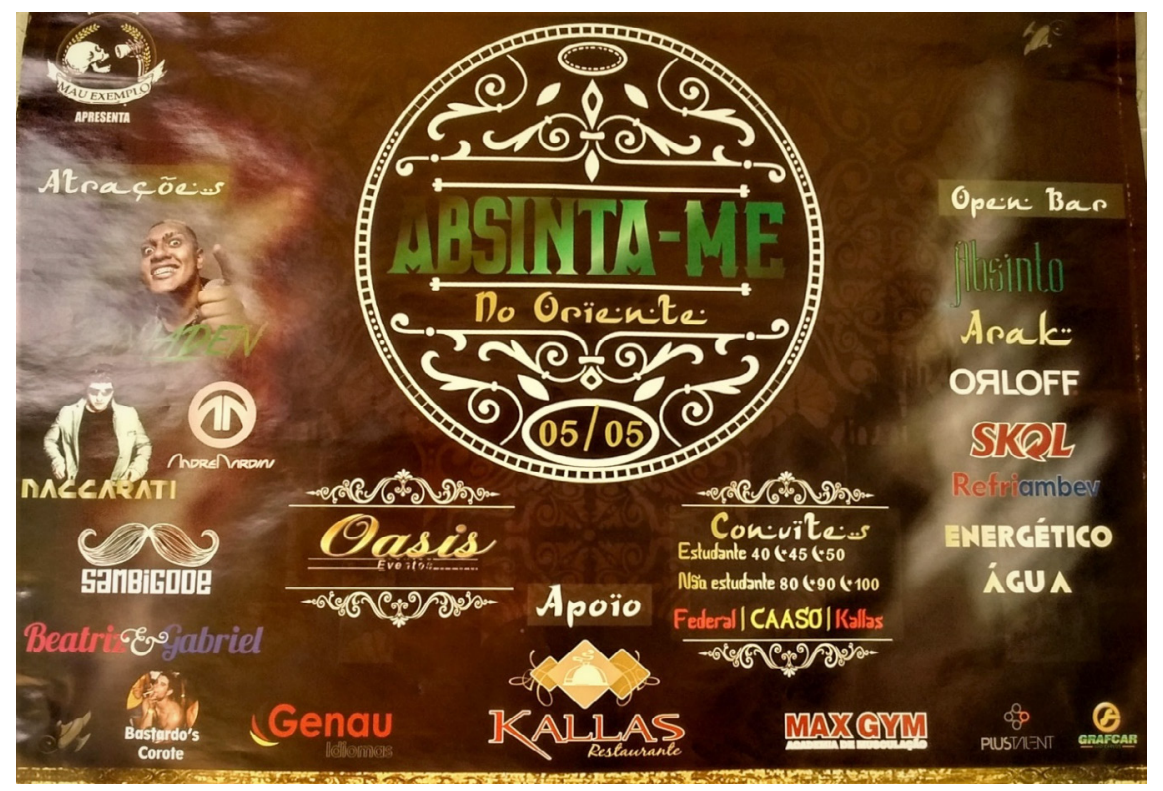

Figura 1. A festa, organizada por uma república estudantil, oferece um open bar com quatro variedades de bebidas alcoólicas, com citação de marcas específicas, além de uma bebida energética. Disponibiliza água (redução de danos?). O preço para não estudantes é o dobro. Oferece cinco atrações musicais diferentes e sugere exotismo. 


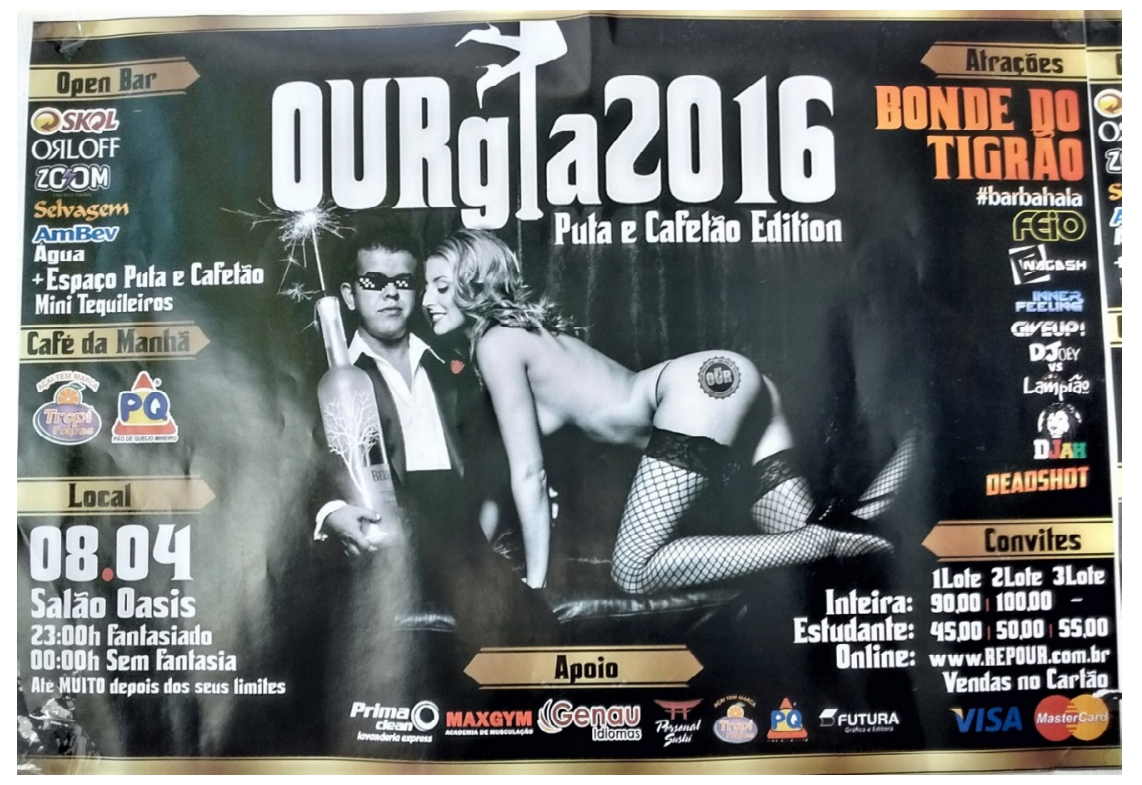

Figura 2. Festa promovida por uma república estudantil, cujo nome serve para o trocadilho com a palavra "orgia". Oferece open bar, com citação das marcas de bebidas a serem consumidas. Na foto, uma das mensagens icônicas, o rapaz segura uma garrafa de seis litros de uma prestigiada marca de vodca, conotando valorização da grande quantidade a ser ingerida; e a mulher tem, em uma nádega, um "carimbo" com o nome da república (conotações de conquista e dominação masculina; objetificação da mulher, mostrada como um insumo da festa; homem como consumidor preferencial de bebidas). Há mensagens linguísticas conotando a grande duração da festa, proposta de extrapolação de limites pessoais e incentivo a fantasiar-se.

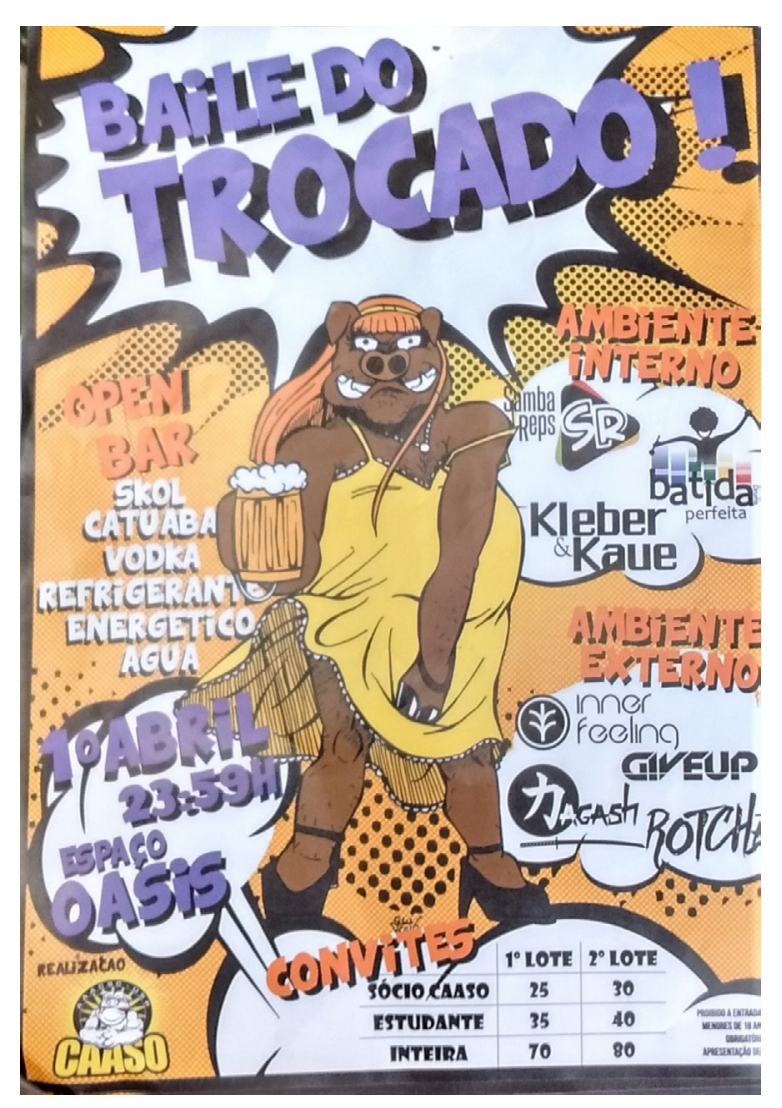

Figura 3. Festa promovida por um centro acadêmico de uma outra universidade da cidade, em esquema de open bar, com citação de marcas específicas. A imagem icônica é um desenho representando um homem travestido e com feições suínas (possível menção cômica à liberação de fantasias sexuais e a questionamentos de identidade de gênero, associada à alusão a efeitos inebriantes e de diversão). Oferece dois espaços simultâneos, com apresentação de gêneros musicais diversos. 


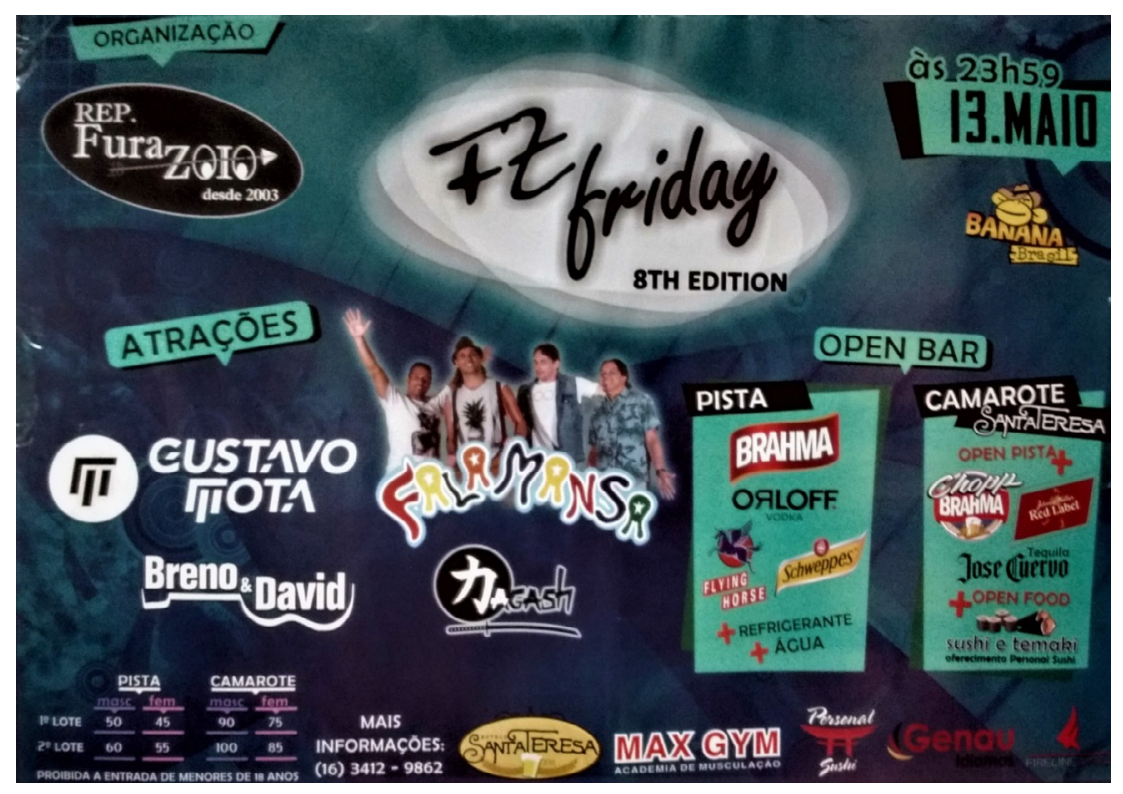

Figura 4. Cartaz de uma festa promovida por uma comunidade estudantil, que menciona a existência já longa tanto da república quanto da festa, em sua oitava edição (referência à tradição, proposição de pertencimento). Esquema de open bar, com várias menções a marcas de bebidas alcoólicas, de diferentes tipos (product placement). Os preços oferecidos às mulheres são menores. Menciona proibição da entrada de menores de 18 anos.

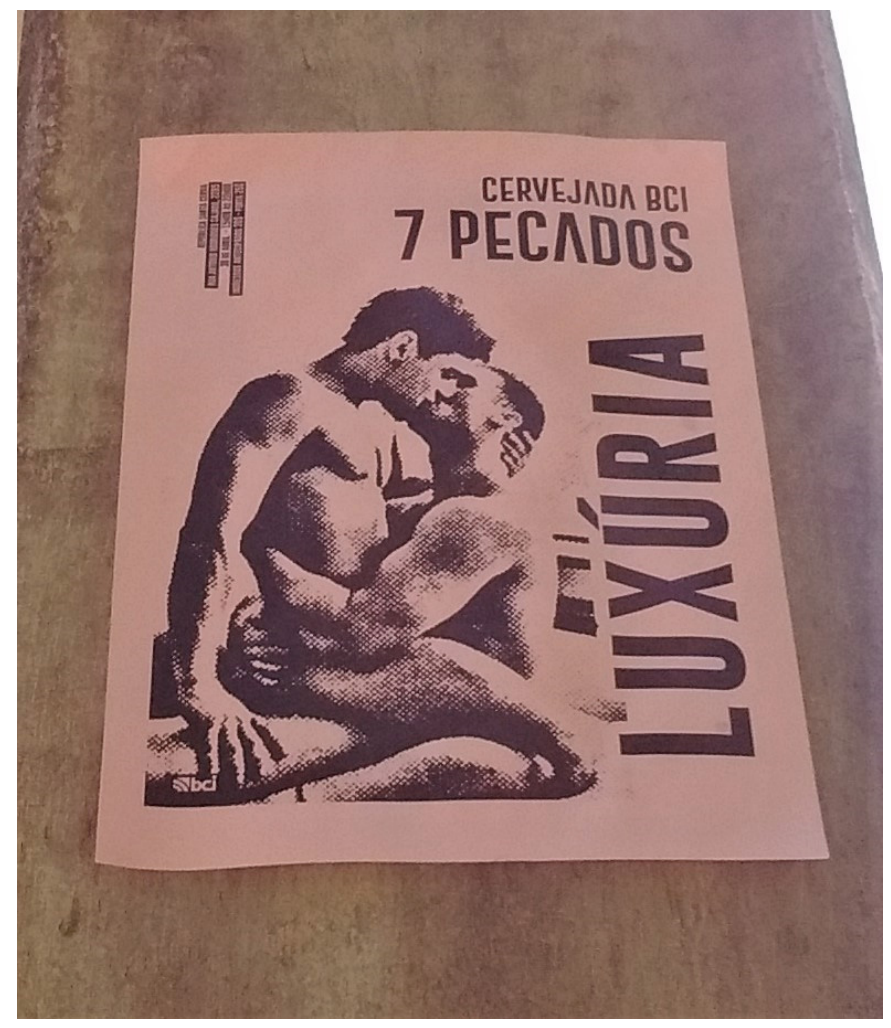

Figura 5. "Cervejada"

promovida por um centro acadêmico da universidade e por uma república estudantil. Mensagem icônica com menções à sensualidade e sexualidade homoerótica, com possível ênfase no público gay. Mensagem linguística com menções ao conceito religioso do pecado da luxúria (que, no sentido dicionarizado, refere-se a "comportamento fora das regras" em relação ao prazer sexual). 


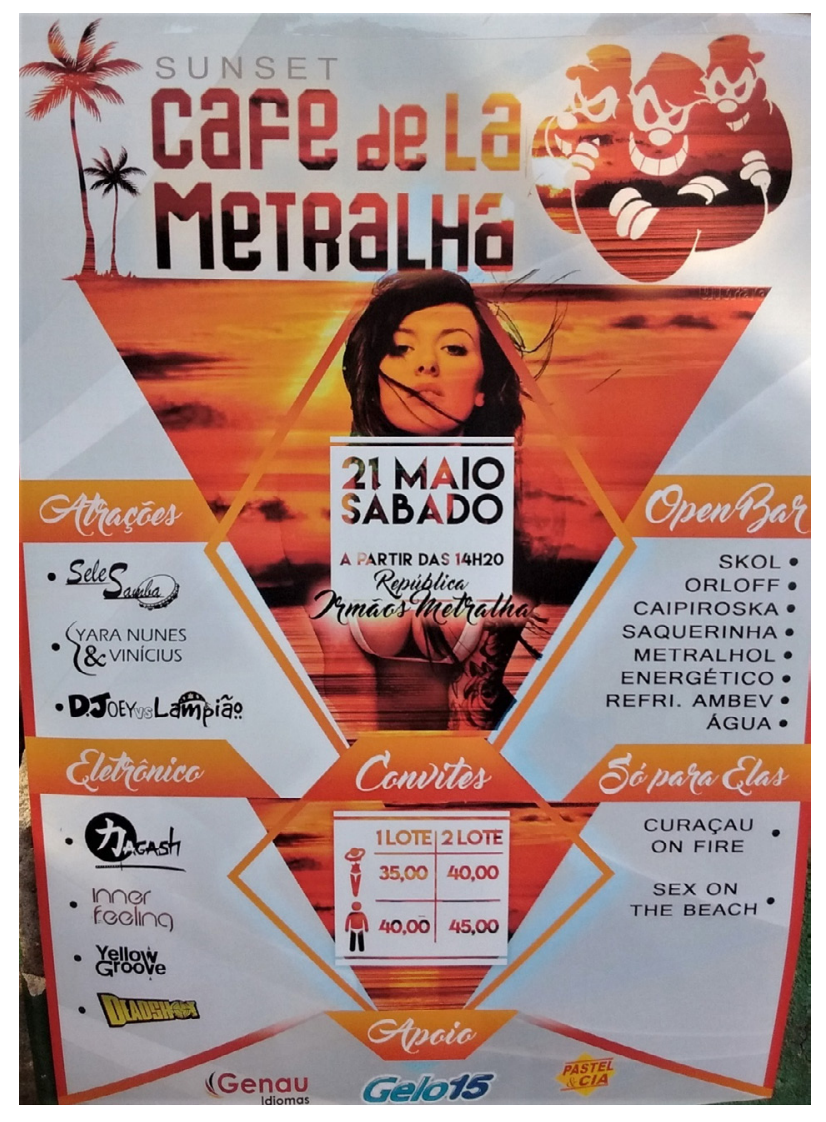

Figura 6. Festa organizada por república estudantil (open bar). Por meio de pictogramas de gênero (mensagem icônica), o evento diferencia os preços para homens e mulheres (com mulheres pagando menos). Mensagem linguística anuncia preparados de bebidas "só para elas" e, no centro do cartaz, há a reprodução de uma foto de uma mulher que remete à sensualidade, aparentemente utilizando a figura feminina, também por meio desta mensagem icônica, como um insumo para a festa. Faz menção cômica a uma irmandade com comportamentos criminosos (referência à história em quadrinhos de uma quadrilha de ladrões atrapalhados). As mensagens plásticas, particularmente a cor preponderante do cartaz, remeteria culturalmente à diversão, ao pouco usual, à extroversão, ao calor, à energia e à atividade.

\section{Resultados}

Ao todo, foram coletadas 257 imagens. Dessas, 170 propagandeavam "festas" e constituíram o corpus de análise. As demais imagens divulgavam atividades esportivas, escolas de línguas, debates não institucionais, encontros religiosos, etc.

Ainda que a distinção entre "festas" e "não festas" nos tenha parecido algo intuitivo, recorremos ao campo da antropologia para fundamentar essa divisão. Consideramos como imagens relativas a festas aquelas que publicizavam eventos que propusessem uma aproximação de indivíduos em espaço e tempo definidos, sugerindo romper com a rotina de trabalho e estudo e propondo uma convivência entusiástica e vivaz, procurando levar a certa efervescência coletiva - na esteira, portanto, da caracterização feita por Émile Durkheim ${ }^{26}$.

À medida que aconteciam a coleta e a análise das imagens do corpus, distinguimos 85 temas, que foram agrupados em seis categorias temáticas (quadro 1). Como costuma ocorrer em estudos qualitativos, a maior concentração de novos temas ocorreu já na análise dos primeiros dados coletados. No presente estudo, isso ocorreu nas vinte primeiras imagens e, a partir daí, novos temas foram apenas esporadicamente identificados, até que cessaram. 
Quadro 1. Categorias temáticas e respectivos temas observados na análise semiótica de imagens veiculadas no campus, levantados a partir das mensagens plásticas, icônicas e linguísticas presentes nas propagandas das festas

\begin{tabular}{|c|c|}
\hline \multirow{18}{*}{ 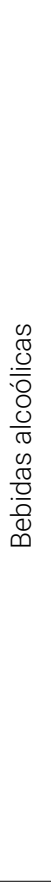 } & Open bar \\
\hline & Menção a bebidas (não a open bar) \\
\hline & Menção à grande quantidade de bebida disponível \\
\hline & Oferecimento de variedade de bebidas \\
\hline & Proposição de grande tempo de uso \\
\hline & Onipresença das referências ao álcool na imagem \\
\hline & Entrada liberada de bebidas na festa \\
\hline & Menções diretas a marcas de bebidas \\
\hline & Intimidade com bebidas alcoólicas \\
\hline & Menção ao efeito de domínio territorial \\
\hline & Menção ao efeito de diversão e alegria \\
\hline & Menção ao efeito de "combustível" para sexualidade \\
\hline & Menção direta a efeitos inebriantes \\
\hline & Naturalização do desejo forte para consumir \\
\hline & Associação com energéticos \\
\hline & Menção a esportes, jogos ou brincadeiras \\
\hline & Homens como consumidores preferenciais \\
\hline & Mulheres como consumidoras preferenciais \\
\hline \multirow{17}{*}{ 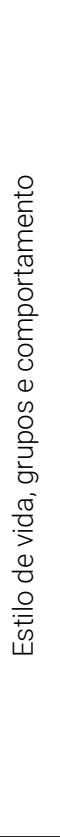 } & Participação em rede social \\
\hline & Participação em grupo seleto \\
\hline & Proposição de pertencimento \\
\hline & Valorização de tradições \\
\hline & Proposição de mudanças de comportamento \\
\hline & Várias dimensões do que é ser estudante \\
\hline & Incentivo à expansão territorial \\
\hline & Convite a exercer atributos positivos (virtudes) \\
\hline & Incentivo a se fantasiar \\
\hline & Exotismo \\
\hline & Sugestão de consumo de outras substâncias psicoativas \\
\hline & Sugestão de anomia/menção cômica à criminalidade \\
\hline & Extrapolação de limites psicoculturais \\
\hline & Postura iconoclasta \\
\hline & Comicidade \\
\hline & Referências a personagens ou brincadeiras infantis \\
\hline & Referências religiosas \\
\hline \multirow{8}{*}{$\begin{array}{l}\frac{0}{0} \\
\frac{\pi}{0} \\
\frac{0}{\bar{\sigma}} \\
\vec{x} \\
\text { 心 }\end{array}$} & Conquista (homens procurando mulheres) \\
\hline & Proposta de "matches", "catch your crush" \\
\hline & Menções a prazer sexual \\
\hline & Potência sexual \\
\hline & Liberação de fantasias sexuais \\
\hline & Menções à sensualidade \\
\hline & Ruptura do padrão sexual feminino tradicional \\
\hline & Menções à homossexualidade \\
\hline
\end{tabular}


Quadro 1. continuação

\begin{tabular}{|c|c|}
\hline \multirow{8}{*}{$\begin{array}{l}\frac{0}{d} \\
\frac{\mathbb{d}}{\mathbb{d}} \\
0\end{array}$} & Reforço ao binarismo de gênero \\
\hline & Dominação masculina \\
\hline & Objetificação do corpo feminino \\
\hline & Mulheres como insumos (preço menor para mulheres) \\
\hline & Questionamento do binarismo de gênero \\
\hline & Dominação feminina \\
\hline & Questionamento (cômico) de identidade de gênero \\
\hline & Ênfase no público gay \\
\hline \multirow{20}{*}{ 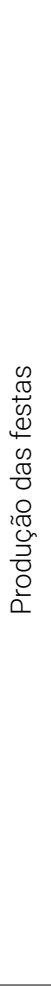 } & Empresa de eventos produzindo \\
\hline & Bar/casa de shows produzindo \\
\hline & Comissão de curso produzindo \\
\hline & Centro acadêmico produzindo \\
\hline & República produzindo \\
\hline & Atlética produzindo \\
\hline & Liga de bateria universitária produzindo \\
\hline & Comunidade extrauniversitária produzindo \\
\hline & Equipe esportiva produzindo \\
\hline & Alimentos como atração \\
\hline & Oferecimento de água/sucos/refrigerantes \\
\hline & Menção à proibição para menores de 18 anos \\
\hline & Posição antidiscriminatória \\
\hline & Proselitismo político \\
\hline & Festas pré-festas ("esquentas") \\
\hline & Ênfase explícita nos estudantes (incluindo preços menores) \\
\hline & Proposição de grande tempo de permanência \\
\hline & Atrações diversificadas \\
\hline & Continuidade com outras mídias \\
\hline & Preocupação com o meio ambiente \\
\hline \multirow{14}{*}{ 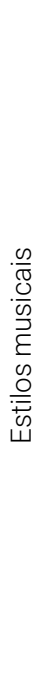 } & Reggae/dub \\
\hline & Eletrônico (diversas variantes) \\
\hline & Funk \\
\hline & Pop \\
\hline & Hip hop \\
\hline & Samba \\
\hline & Sertanejo \\
\hline & Rock (diversas variantes) \\
\hline & Pagode \\
\hline & Sertanejo universitário \\
\hline & Axé \\
\hline & Forró \\
\hline & Rap \\
\hline & Gênero musical não identificado \\
\hline
\end{tabular}




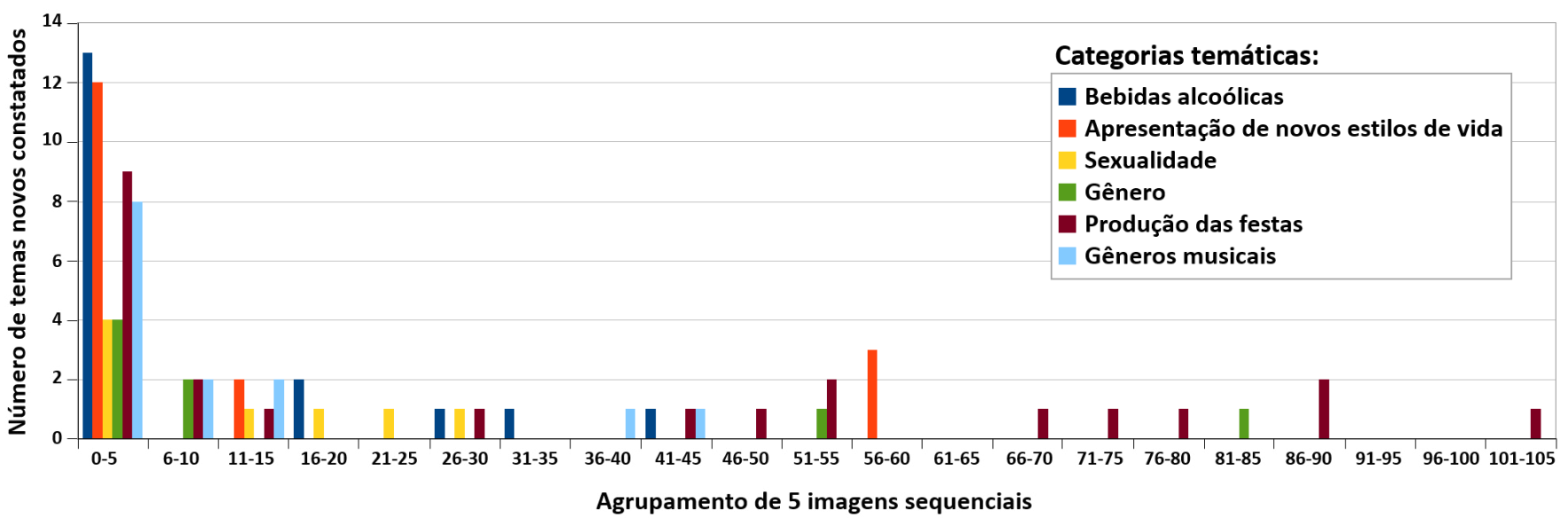

Gráfico 1. Ocorrências de novos temas observados nas imagens publicitárias de festas veiculadas no campus universitário, para cada uma das seis categorias

* Para facilidade de visualização, cada barra corresponde à análise de conjuntos de cinco imagens sequenciais. Observa-se uma concentração de ocorrências de novos temas nas vinte primeiras imagens. A categoria "produção das festas" foi considerada saturada na 105a imagem; a categoria "gênero", na 85a imagem; e as demais categorias, na 60 imagem, aproximadamente, do total de 170 imagens analisadas.

Para cada uma das seis categorias formuladas, foi preenchido um quadro em que assinalamos em qual imagem cada tema apareceu pela primeira vez e em quais imagens esses temas reapareceram. As análises sequenciais, imagem após imagem, permitiram distinguir o ponto aproximado em que ocorreu a saturação teórica ${ }^{27,28}$, isto é, o momento em que os pesquisadores se sentiriam seguros em interromper a análise de novas imagens, ou seja, quando não havia mais a expectativa de identificar novos temas nas imagens subsequentes. O gráfico 1 mostra a dinâmica geral dessa análise dos dados. Observa-se que cada categoria apresentou um ponto de saturação diferente, sendo a categoria "Produção das festas" a última a ser saturada, na imagem de número 105. Entretanto, as análises continuaram até a imagem 122 (correspondente ao oitavo mês de coleta de dados), para que os pesquisadores se certificassem do fato de que novos temas não seriam mais identificados.

Alguns dados quantitativos simples, como a frequência com que determinados temas ocorreram, tiveram também valor para os nossos objetivos, pois ilustraram os temas mais salientados por aqueles que elaboraram as imagens e produziram as festas. No entanto, os resultados qualitativos - ou seja, as análises pormenorizadas das imagens, a identificação dos vários temas e as conseguintes formulaçôes e discussões das categorias - foram o foco da investigação

\section{Discussão}

As figuras 1 a 6 servem de ilustração dos temas mencionados na discussão das categorias. 


\section{Bebidas alcoólicas: quantidades, tipos e efeitos}

Alusões a bebidas alcoólicas foram praticamente ubíquas no corpus. Em cerca de dois terços delas (62\%) ocorreram mençôes a open bar - isto é, o frequentador teria o direito de consumir livremente todas as bebidas oferecidas, sem pagamentos extras além do ingresso da festa. Em um quinto das imagens (22\%) houve menções à disponibilidade de bebidas alcoólicas na festa, porém, sem oferta de open bar, dando-se a aquisição das bebidas por meio da compra direta. Em alguns casos havia, simplesmente, referências a "cervejadas". Adicionalmente, em cerca de um quinto das imagens (17\%), houve o que chamamos de onipresença de mençốes ao álcool, ocupando metade ou mais da área da imagem analisada. Também cerca de um quinto das imagens (19\%) assinalou, por meio de símbolos icônicos ou linguísticos, a disponibilidade de uma grande quantidade de bebidas alcoólicas.

Adicionalmente a esta grande quantidade de bebidas propagandeada, metade das imagens mencionou também a disponibilidade de grande variedade de tipos de bebidas (52\%), como cerveja, vodca, aguardente, um preparado alcoólico propagandeado como afrodisíaco, etc. Cerca de um terço das imagens (36\%) fez mençóes diretas a determinadas marcas de bebidas e em apenas dois dos eventos propagandeados permitia-se a entrada liberada na festa com bebidas trazidas de fora do ambiente festivo. Em cerca de um décimo delas, aludiu-se à grande duração da festa, dispondo o frequentador, portanto, de grande tempo para fazer uso.

Houve, desse modo, uma forte valoração das bebidas alcoólicas nesses ambientes de festas propagandeadas no campus. Elas foram divulgadas não só como parte do evento, mas também como disponíveis em grande variedade e quantidade - em geral ilimitada, na forma de open bar.

Além de ofertar o consumo do álcool, as imagens pareceram servir à estratégia de product placement de certas marcas de bebidas, propagandeadas sem que recorressem a anúncios publicitários explícitos. A inferência imediata do emprego deste marketing indireto é a possível existência de uma relação comercial entre quem produz as festas e as empresas distribuidoras e/ou produtoras de determinadas marcas de bebidas. Assim, o marketing das festas pareceu se apoiar no marketing e no prestígio comercial das marcas de bebidas e estas, por sua vez, pareceram aproveitar-se dos eventos para tentar atrair e fidelizar clientes. A grande quantidade de bebidas oferecidas foi, assim, restrita a certas marcas oferecidas dentro das festas, fazendo com que o território do campus universitário possivelmente servisse a propósitos comerciais de determinadas marcas. Mesmo com grande variedade de tipos de bebidas, na maioria das vezes o frequentador só poderia consumir, conforme especificado nas imagens, produtos de marcas específicas que se encontrariam disponíveis, impossibilitando escolhas individuais naqueles contextos.

O consumo de álcool pareceu ser incentivado também por meio de símbolos que conotavam alcançar alguns alvos: o efeito inebriante (14\%); o efeito afrodisíaco ou de "combustível” para o exercício da sexualidade (9\%); a sensação de domínio territorial (13\%) e um estado de divertimento e alegria (18\%). A proposição de associação de bebidas alcoólicas com bebidas "cafeinadas" ( $23 \%$ das imagens) com o possível intuito de compensar efeitos sedativos do álcool e a associação de álcool com atividades lúdicas e esportes (14\%) reforçam as hipóteses de pesquisas que mostram alta associação entre 
uso de bebidas alcoólicas e de energéticos ${ }^{29}$ e um maior consumo de álcool entre atletas universitários ${ }^{30}$.

Algumas imagens conotaram certa naturalização do desejo forte de consumir (8\%), ou seja, que o desejo intenso de consumir bebidas alcoólicas seria algo naturalmente esperado. Outras imagens transmitiram a ideia de intimidade com as bebidas (16\%), sugerindo que o público já teria integrado o uso do álcool em sua vida. Um reforço dessa ideia de naturalização do comportamento de procura de álcool nas festas se verificou nas poucas menções implícitas ou explícitas aos efeitos inebriantes e euforizantes das bebidas alcoólicas, em contraposição à vasta gama de imagens que oferecem um open bar variado e extenso. Portanto, parece partir-se do pressuposto de que os efeitos inebriantes e euforizantes do álcool já estariam presentes de antemão nos repertórios interpretativos dos universitários, não sendo necessário reforçar essa associação na publicidade das festas. No mesmo sentido, foram observadas escassas mençôes a outros efeitos alcoólicos percebidos como positivos.

Em relação ao gênero dos consumidores, cerca de 15\% dos cartazes continham imagens icônicas representando o público masculino como consumidores preferenciais e, em menor monta (4\%), o público feminino. Portanto, observa-se que, em geral, os materiais publicitários tenderam a não eleger um gênero específico como alvo preferencial, em consonância com os estudos que mostram que o padrão de consumo de bebidas alcoólicas entre homens e mulheres jovens praticamente se equivale na atualidade ${ }^{29}$. Porém, entre os materiais que elegem um gênero como consumidor preferencial, a maioria se dirige ao público masculino, assemelhando-se ao padrão geral a que a publicidade das bebidas alcoólicas costuma se dirigir. Os materiais que elegem como consumidor preferencial o público feminino talvez estejam indo ao encontro de uma tendência publicitária de mudança do público-alvo tradicional na publicidade das bebidas.

\section{Estilo de vida, grupos e comportamento}

Esta categoria e as duas seguintes ("Sexualidade" e "Gênero") nos parecem particularmente importantes, pois, tipicamente, os estudantes universitários estão vivenciando a fase final da adolescência ao ingressarem e cursarem os primeiros anos de seus cursos presenciais de graduação. Estão, portanto, experimentando o início de suas vidas sexuais e configurando progressivamente suas identidades pessoais e suas redes sociais de apoio.

Os rituais festivos procuram diminuir distâncias entre as pessoas e, assim, não se estranhou que cerca de metade das imagens usava como um recurso de marketing a ideia de incentivar o universitário a participar de uma rede social, fosse ela uma república estudantil, uma associação atlética ou um centro acadêmico estudantil (50\%). Cerca de um terço das imagens (34\%) trouxe conotações de participação em um grupo relativamente seleto, como membros de um curso universitário específico ou de uma república estudantil com tradição na cidade. Quase metade (46\%) trouxe símbolos que conotam a ideia de proposição de pertencimento a grupos. Dois quintos das imagens (41\%) trouxeram símbolos que ancoravam as festas a tradiçóes, como referências a edições em anos anteriores e referências à própria tradição do grupo produtor da festa. 
Esses recursos podem servir de incentivo ao jovem universitário para participar do evento, pois, nessa fase do ciclo vital, é comum que se depare com maior insegurança social. A busca da aceitação, coesão e pertencimento social parece ser justamente o que as imagens sugeriam ser facilitado nas situaçóes festivas.

Observa-se que o recurso à tradição é um contraponto à proposição do afrouxamento de regras sociais, outro tema presente no corpus. No entanto, o afrouxamento temporário das regras de convívio pode, em tese, estar a serviço da necessidade de reafirmação da ordem, a ser reestabelecida no momento seguinte. A proposta de momentos específicos para afrouxar regras pode ser uma das maneiras de reafirmá-las em todos os demais momentos.

As imagens muitas vezes sugeriram mudanças de comportamentos (20\%) e incentivo a se fantasiar (20\%) e fizeram referências a paisagens e contextos exóticos (23\%), aparentemente incentivando uma expansão da territorialidade do espectador por meio de novas experiências socioculturais (34\%). Praticamente metade das imagens (45\%) faz menção ao que seriam as variadas dimensões de ser universitário, sugerindo que a ida ao evento festivo faria parte deste novo status social. Menos de um décimo das imagens incentivava de forma direta o universitário a exercer atributos tradicionalmente considerados como especialmente positivos e virtuosos, como a prática esportiva e de amizade (8\%).

Uma parte das imagens sugeriu expansão ou extrapolação de certos limites psicossociais menos facilmente reversíveis (20\%). Isso se constatou, por exemplo, em mensagens icônicas que instigavam à anomia social e em menções, mesmo que cômicas, a comportamentos criminosos (13\%). Isso também pareceu ocorrer na sugestão de consumo de outras substâncias psicoativas além do álcool (25\%), como o de substâncias psicodislépticas e, também, em sátiras a instituições religiosas (postura iconoclástica $3 \%$ ). Cartazes que veiculam mensagens de mudanças de comportamento desses tipos foram mais frequentes do que aqueles que divulgam mensagens de comportamentos geralmente considerados como virtuosos.

Outro recurso retórico utilizado foi a comicidade (19\%). Houve ainda referências a personagens ou brincadeiras infantis (8\%), talvez significativo para alguns espectadores em função da transição etária em que se encontram. Uma imagem fez uma referência religiosa ao rastafarianismo e indiretamente, portanto, ao consumo de cânabis.

\section{Sexualidade}

Algumas imagens associaram o consumo de álcool ao exercício da sexualidade, utilizando símbolos que conotavam prazer sexual (16\%), sensualidade (22\%), potência sexual (15\%) e liberação de fantasias sexuais (23\%). Essa estratégia pareceu dirigirse especificamente ao público heterossexual masculino. Alguns cartazes portavam símbolos que remetiam ao comportamento de busca sexual, por vezes especificando a ideia de conquista masculina, ou seja, de um homem buscando mulheres (9\%), mas em nenhum cartaz ocorreu o oposto (mulheres buscando homens). Outros cartazes não trouxeram essa especificidade, com propostas de "matches" e de "catch your crush", sem sugestôes de qual gênero procuraria e qual gênero seria procurado (10\%). Algumas poucas imagens trouxeram mençóes à sexualidade homoerótica $(3 \%)$ e à ruptura de um comportamento padrão sexual feminino tradicional (1\%). 
Observou-se, então, a concomitância de imagens que conotavam dois extremos: enquanto algumas foram construídas de maneira tradicional (hegemonia masculina no comportamento de abordagem sexual), outras apresentam rupturas com essas tradiçóes. Curiosamente, essas mudanças de padróes culturais quanto à sexualidade, suscitadas em algumas imagens, não pareceram se associar a propostas de mudanças dos padróes de consumo de álcool: a ênfase no consumo em grande quantidade continuou sendo igualmente utilizada como recurso propagandístico, independentemente do tipo de apelo ao exercício da sexualidade que o cartaz tenha feito.

\section{Gênero}

Observou-se uma ratificação da ideia de "binarismo de gênero", explícita em cerca de um quarto das imagens (25\%). Em geral, isso se deu pela ênfase nos preços diferenciados para homens e mulheres, quase sempre utilizando pictogramas de gênero, ou seja, desenhos figurativos para designá-los.

Algumas imagens pareceram-nos reificar aspectos culturais de dominação masculina sobre as mulheres (16\%), por vezes uma clara objetificação da mulher (9\%), apresentando-as como atrações da festa. Pareceu haver muitas vezes, de fato, uma utilização da imagem da mulher como um insumo (20\%) para a festa. Isso se traduziu como preços menores para as mulheres, provavelmente uma estratégia de marketing para atrair o público heterossexual masculino; portanto, as mulheres aparecem "servindo como isca" para atrair frequentadores do sexo masculino, utilizando expressão recentemente manifestada em decisão judicial sobre preços diferenciados segundo o sexo ${ }^{31}$.

Por outro lado, observou-se que alguns outros cartazes seguiram a tendência de romper esses padróes culturais tradicionais com simbologias que remeteram à "quebra do binarismo de gênero" (12\%), à "dominação feminina” (entre aspas, pois obviamente não se trata de uma categoria socioantropológica, traduzindo-se como festas específicas para as mulheres ou mostrando imagens fortes e onipresentes de mulheres $-8 \%$ ), ao questionamento cômico da identidade de gênero (7\%) e à ênfase no público gay (2\%). Essas ocorrências reforçam a ideia de convivência de tendências culturais distintas e mesmo opostas no que concerne às questóes de gênero no meio universitário. No entanto, a maior parte das imagens nos pareceu ainda reificar comportamentos que asseguraram certas prerrogativas masculinas e, novamente, não se observou mudança no padrão de marketing relativo às bebidas alcoólicas entre um extremo e outro dessas tendências: mesmo nas imagens que parecem querer romper com o binarismo de gênero, são veiculadas propostas de uso frequente, naturalizado e em grandes quantidades.

\section{Produção de festa}

Nesta categoria, notamos que a maioria das festas é produzida para os universitários e pelos próprios universitários, que parecem ver nesse tipo de produção uma chance de atividade econômica, com a criação de empresas especializadas em produzir eventos. A maior parte das festas é produzida por repúblicas (40\%), centros acadêmicos (15\%), comissões de curso (9\%) e atléticas (7\%). 
Assim como nas categorias anteriores, embora haja uma ampla variedade de tipos de produções de festas, há menções ao uso de bebidas alcoólicas em quase todos os cartazes, sendo que muitos divulgam marcas específicas das bebidas. A forte relação da indústria do álcool com as associaçóes atléticas universitárias foi estudada no Brasil ${ }^{32}$. Nossos dados indicam, porém, que o marketing de empresas distribuidoras e/ ou produtoras de certas marcas de bebidas alcoólicas se ancora e se aplica às variadas coletividades estudantis universitárias, não se limitando às atléticas. Em nosso campo de estudo, a maior parte das festas e, portanto, das publicidades, foi feita por repúblicas universitárias, e não pelas atléticas. Como muitos desses eventos de repúblicas têm parcerias com marcas de bebidas (o mesmo ocorrendo com centros acadêmicos, comissóes de curso e atléticas), levantamos a hipótese de uma intensa e já estruturada capilaridade das empresas distribuidoras e/ou produtoras de certas marcas de bebidas alcoólicas junto aos universitários.

Complementarmente, algumas empresas de eventos (17\%) e bares ou casas de shows (2\%) também divulgaram seus eventos no campus, provavelmente aproveitando a particular oportunidade de visualização e divulgação dos eventos voltados para o público jovem. Além dessas, a própria comunidade (2\%) e equipes esportivas ( $3 \%$ ) divulgaram seus eventos. Assim, a soma das produções não universitárias totaliza 24\%, menos do que o total das festas promovidas apenas pelas repúblicas, proporção que diminuiria ainda mais se fosse considerado que algumas dessas empresas de festas são dirigidas por estudantes.

Na produção das festas, alguns cartazes trouxeram símbolos que remetem à ideia de redução de danos do consumo de álcool, mesmo que possivelmente não como uma estratégia proposital. Oferecem a oportunidade de os participantes, por exemplo, hidratarem-se e alimentarem-se: há a presença de alimentos como atração (25\%), oferecimento de água e suco (25\%) ou de refrigerantes (43\%). Entre as bebidas não alcoólicas, há uma proporção de quase o dobro de menções aos refrigerantes e sucos em relação à água.

Embora preconizada pela Lei Estadual n 14.592 e pela Lei Federal no $13.106^{33,34}$, apenas um décimo das imagens trouxe impresso o aviso de proibição do evento para menores de 18 anos, fato instigante se fosse considerado que parte do público universitário tem menos de 18 anos e estaria, portanto, exposta a ofertas ilegais de bebidas alcoólicas.

Associada à ideia de as festas serem de universitários para universitários, algumas imagens possuem símbolos que dão ênfase explicita a esse público, incluindo preços menores para estudantes (15\%).

Algumas imagens possuem simbologias que remetem a um a grande tempo de permanência na festa (11\%), enquanto outras fazem menções a serem festas pré-festas ou "esquentas" (festa que serve de preparação para uma festa maior) (3\%), indicando uma cultura festiva disseminada. Como foram reunidas imagens de 170 propagandas de festas nos 12 meses de coleta, houve uma média de 3,5 festas por semana. Isso pode significar uma oferta para satisfazer uma expectativa dos estudantes ou uma oferta que, na lógica econômica, objetivaria naturalizar as festas com grande oferta de bebidas como algo próprio da vida universitária.

Mais de um quarto das imagens indicou "continuidade com outras mídias" (28\%) para obtenção de informaçóes sobre o evento via internet, indo ao encontro da ideia 
de uma crescente sociabilidade virtual, concomitante à sociabilidade clássica exercida pessoalmente, e também possivelmente conotando a profissionalização desses eventos, ao se adotar a técnica de marketing de fragmentação dos veículos de divulgação. Outro dado que suporta essa ideia de profissionalização é a oferta de atraçóes diversificadas além da música, do open bar e do open food, incluindo a oferta de brincadeiras variadas $(26 \%)$.

Apenas uma imagem trouxe a questão da preocupação com a discriminação social, com mensagens linguísticas que diziam não tolerar qualquer atitude de caráter sexista, racista ou homofóbico, o que vai ao encontro do anteriormente comentado possível, ainda que tímido, movimento de quebra de padróes conservadores de sociabilidade e de incentivo à maior diversidade étnica e de gênero dentro da universidade. No entanto, a própria preocupação que esses cartazes explicitam indica que práticas discriminatórias durante as festas podem ser frequentes.

Finalmente, uma minoria de cartazes explicitou outras intenções políticoideológicas, mostrando preocupaçóes com o meio ambiente (1\%) ou fazendo um proselitismo político explícito (2\%).

\section{Estilos musicais}

Em razão de suas origens histórico-culturais, de fenômenos afetivos e cognitivos e motivaçóes, os gêneros musicais tipicamente estão associados a sistemas de convençóes e de expectativas do público consumidor de música ${ }^{35}$.

As mençôes aos tipos de músicas que seriam ouvidas nas festas propagandeadas foi algo difundido extensamente nos anúncios de festas, tendo isso se dado por meio de citação direta dos gêneros musicais, pela menção às bandas e aos disc jockeys (DJs) que estariam presentes. Elementos plásticos presentes nos anúncios também se associaram aos diferentes estilos. Geralmente, os cartazes anunciavam uma mescla de diversos gêneros musicais que seriam tocados sequencialmente ou, em festas maiores, em palcos diferentes, sendo este um possível indicativo das afinidades culturais diversas e simultâneas do público frequentador.

O gênero mais citado no corpus foi o eletrônico (34\%), em suas numerosas variantes dançantes. Criada com equipamentos eletrônicos e softwares de composição e reproduzidas ou mixadas segundo a escolha de um DJ, já se levantou a hipótese de que facilite, por meio das seguidas repetiçóes de sequências rítmicas, um estado de transe em alguns ouvintes ${ }^{36}$. Associa-se fortemente à cultura e às festas rave, caracteristicamente permeadas pelo uso de substâncias psicoativas; parte das imagens analisadas contêm elementos plásticos e icônicos que remetem a sonhos, fantasias oníricas e uso de alucinógenos, ratificando análises etnográficas recentes nesses cenários subculturais ${ }^{37}$.

O segundo gênero mais prevalente no corpus foi o funk (17\%) que, no Brasil, tem sua origem nas favelas cariocas. Nas imagens com predomínio de menções ao funk, há referências a elementos e estilos de vida que os seus subgêneros abordam, como comportamentos socialmente desviantes e/ou relacionados ao consumo, à sexualidade e ao corpo feminino. Estudos antropológicos também associaram o gênero a um escape afetivo de problemas estruturais como racismo e pobreza ${ }^{38}$. 
Dentre os gêneros de desenvolvimento mais tipicamente brasileiros apareceram o sertanejo e sertanejo universitário (17\% e $7 \%$, respectivamente), associados comumente às ideias de simplicidade, vida interiorana e sentimentalismo. O samba (17\%), pagode (8\%), forró (7\%) e axé (4\%) se associam mais comumente a contentamento e extroversão ${ }^{36}$. Não encontramos menção ao estilo MPB.

O rock (17\%), desde suas vertentes mais românticas até o punk, associa-se a uma variedade de estilos de vida, carregando, porém, o estereótipo de ser ouvido por pessoas com "alma jovem" 39 .

Outros gêneros foram citados menos frequentemente. Em cerca de um sexto dos cartazes (16\%), não foi possível identificar que gêneros musicais eram referidos.

Já se levantou a hipótese, a partir da perspectiva individual de ouvintes adolescentes e jovens, de que a música pode ajudar a combater sentimentos egodistônicos e representar uma "fonte vital de energia" para eles ${ }^{39}$. Porém, considerando a tese de que as vivências musicais dos indivíduos, além de provir de sentidos pessoais, derivam também de significados construídos coletivamente ${ }^{40}$, a justaposição de gêneros musicais em um mesmo evento ratifica a ideia da convivência de diversas sensibilidades e afinidades culturais no meio universitário.

\section{Conclusões}

Os estudantes do campus de São Carlos da UFSCar estiveram expostos entre março de 2016 e abril de 2017 a uma chamativa quantidade de cartazes que propagandeavam festas - em média, foram anunciadas mais de três por semana.

Nas imagens, uma ampla variedade de mensagens foi veiculada a partir de significantes plásticos, icônicos e linguísticos nelas presentes. Foram veiculadas variadas motivaçôes festivas; atrações de variados tipos; estilos de vida e estilos musicais; reificaçôes e algumas poucas contestaçôes de configuraçốes tradicionais de gênero; incentivos a comportamentos sexuais; ancoragens das festas a determinadas tradições - e proposiçôes de rupturas de outras -; e finalidades econômicas diversas, abordando, assim, uma ampla segmentação do público-alvo.

Em meio à gama de mensagens encontradas nas imagens e apesar de sua ampla segmentação, majoritária e difusamente se encontram nelas menções de incentivo ao consumo de bebidas alcoólicas e, menos frequentemente, a outras substâncias psicoativas. Constatou-se uma forte ênfase na variedade de bebidas que poderiam ser consumidas nas festas e, sobretudo, na quantidade de bebidas que seriam disponibilizadas. Comumente, houve uma explícita divulgação de certas marcas de bebidas por meio de marketing indireto, sugerindo que as produções dessas festas se configuram como atividades econômicas relacionadas a empresas distribuidoras e/ou produtoras de certas marcas de bebidas alcoólicas.

O processo de socialização dos estudantes universitários parece permeado, portanto, por uma constante alternância entre tempo de estudo e trabalho e tempo de lazer - este último, aparentemente, correspondendo frequentemente a festas em que o consumo em grande quantidade de bebidas alcoólicas é incentivado. Os elementos persuasivos ao consumo que são veiculados por meio das imagens são variados, envolvendo apelos à associação com o exercício de sexualidade, a reificaçôes e questionamentos de valores 
tradicionais, ao prazer, à alegria, à ideia de domínio territorial, à apresentação de novos comportamentos e estilos de vida e ao enfrentamento de problemas e dificuldades psicossociais.

Os achados também indicam uma relação, mesmo que informal e não explícita em termos econômicos ou administrativos, entre a produção e o comércio de bebidas e o território do campus universitário, que termina por servir de veículo às propagandas. Observou-se que a maioria dos cartazes não segue a legislação e a regulamentação para sua produção, comumente propagandeando e oferecendo a oportunidade de consumo de bebidas alcoólicas para menores e realizando diferenciação do preço para as mulheres.

\section{Contribuições dos autores}

Emílio Martins Curcelli realizou a coleta de dados e participou da análise, da discussão dos resultados e da redação do manuscrito. Bruno José Barcellos Fontanella concebeu e delineou o projeto de pesquisa, supervisionou a coleta de dados e participou da análise, da discussão dos resultados e da redação do manuscrito.

\section{Agradecimento}

Ao CNPq, pela concessão de bolsa de iniciação científica a Emílio Martins Curcelli (Pibic, processo $120018 / 2016-0)$.

\section{Direitos autorais}

Este artigo está licenciado sob a Licença Internacional Creative Commons 4.0, tipo BY (https://creativecommons.org/licenses/by/4.0/deed.pt_BR).

(cc))

\section{Referências}

1. Osse CMC, Costa II. Saúde mental e qualidade de vida na moradia estudantil da Universidade de Brasília. Estud Psicol (Campinas). 2011; 28(1):115-22.

2. Laranjo THM, Soares CB. Moradia universitária: processos de socialização e consumo de drogas. Rev Saude Publica. 2006; 40(6):1027-34.

3. Souza GHS, Coelho JAPM, Lima NC, Queiroz JVQ. Marketing informal: um modelo de comercialização pautado em jeitinho brasileiro, informalidade e empreendedorismo. Rev Bras Mark. 2014; 13(3):63-77.

4. Falcão ICL, Rangels ML. Controle sanitário da propaganda de bebidas alcoólicas no Brasil: estudo dos projetos de lei de 1988 a 2004. Cienc Saude Colet. 2010; $15(3): 3433-42$.

5. Wagner GA, Oliveira LG, Barroso LP, Nishimura R, Ishihara LM, Stempliuk VA, et al. Drug use in college students: a 13-year trend. Rev Saude Publica. 2012; 46(3):497504. 
6. Rosa MI, Caciatori JFF, Panatto APRO, Silva BR, Pandini JC, Freitas LBS, et al. Uso de tabaco e fatores associados entre alunos de uma universidade de Criciúma (SC).

Cad Saude Colet. 2014; 22(1):25-31.

7. Castaño-Perez GA, Calderon-Vallejo GA. Problemas associados ao consumo de álcool em estudantes universitários. Rev Lat Am Enfermagem. 2014; 22(5):739-46.

8. Nunes JM, Campolina LR, Vieira MA, Caldeira AP. Consumo de bebidas alcoólicas e prática do binge drinking entre acadêmicos da área da saúde. Rev Psiquiatr Clin. 2012; 39(3):94-9.

9. Silva LVER, Malbergier A, Stempliuk VA, Andrade AG. Factors associated with drug and alcohol use among university students. Rev Saude Publica. 2006; 40(2):280-8.

10. Nemer ASA, Fausto MA, Silva-Fonseca VA, Ciomei MH, Quintaes KD. Pattern of alcoholic beverage consumption and academic performance among college students. Rev Psiquiatr Clin. 2013; 40(2):65-70.

11. Pillon SC, O'brien B, Chavez KAP. A relação entre o uso de drogas e comportamentos de risco entre universitários brasileiros. Rev Lat Am Enfermagem. 2005; 13(2):116976.

12. Coelho IZ, Bastos JL, Celeste RK. Moderators of the association between discrimination and alcohol consumption: findings from a representative sample of Brazilian university students. Trends Psychiatry Psychother. 2015; 37(2):72-81.

13. Andrade AG, Duarte PCAV, Barroso LP, Nishimura R, Alberghini DG, Oliveira LG. Use of alcohol and other drugs among Brazilian college students: effects of gender and age. Rev Bras Psiquiatr. 2012; 34(3):294-305.

14. Oliveira LG, Barroso LP, Wagner GA, Ponce JC, Malbergier A, Stempliuk VA, et al. Drug consumption among medical students in São Paulo, Brazil: influences of gender and academic year. Rev Bras Psiquiatr. 2009; 31(3):227-39.

15. Colares V, Franca C, Gonzalez E. Condutas de saúde entre universitários: diferenças entre gêneros. Cad Saude Colet. 2009; 25(3):521-8.

16. Vendrame A, Pinsky I, Faria R, Silva R. Apreciação de propagandas de cerveja por adolescentes: relaçôes com a exposição prévia às mesmas e o consumo de álcool. Cad Saude Colet. 2009; 25(2):359-65.

17. Pinsky I, Jundi S. O impacto da publicidade de bebidas alcoólicas sobre o consumo entre jovens: revisão da literatura internacional. Rev Bras Psiquiatr. 2008; 30(4):36274.

18. Pedrosa AAS, Camacho LAB, Passos SRL, Oliveira RVC. Consumo de álcool entre estudantes universitários. Cad Saude Colet. 2011; 27(8):1611-21.

19. Musse AB. Apologia ao uso e abuso de álcool entre universitários: uma análise de cartazes de propaganda de festas universitárias. SMAD Rev Eletronica Saude Mental Alcool Drog. 2008; 4(1):1-10.

20. Romera LA. Lazer e festas: estudo sobre os modos de divulgação de bebidas nos campi universitários. Cad Ter Ocup UFSCar. 2014; 22 Suppl:95-102.

21. Joly M. Introdução à análise da imagem. 14a ed. Campinas: Papirus; 2012.

22. Barthes R. Elementos de semiologia. 19a ed. São Paulo: Cultrix; 2012.

23. Eco U. Tratado geral de semiótica. 5a ed. São Paulo: Perspectiva; 2017.

24. Peirce CS. Semiótica. 4a ed. São Paulo: Perspectiva; 2015.

25. Saussure F. Curso de linguística geral. São Paulo: Cultrix; 2006. 
26. Amaral L, Mesquita WAB, Perez LF. A festa como perspectiva e em perspectiva. Rio de Janeiro: Garamond; 2012.

27. Fontanella BJB, Ricas J, Turato ER. Amostragem por saturação em pesquisas qualitativas em saúde: contribuiçóes teóricas. Cad Saude Colet. 2008; 24(1):17-27.

28. Fontanella BJB, Lucchesi BM, Saidel MG, Ricas J, Turato ER, Melo DG. Amostragem em pesquisas qualitativas: proposta de procedimentos para constatar saturação teórica. Cad Saude Colet. 2011; 27(2):388-94.

29. Brasil. Presidência da República. Secretaria Nacional de Políticas sobre Drogas. Andrade AG, Duarte PCAV, Oliveira LG, organizadores. I Levantamento Nacional sobre o Uso de Álcool, Tabaco e Outras Drogas entre Universitários das 27 Capitais Brasileiras. Brasília: SENAD; 2010.

30. Santos MBP, Tinucci T. O consumo de álcool e o esporte: uma visão geral em atletas universitários. Rev Mackenzie Educ Fis Esporte. 2004; 3(3):27-43.

31. Tribunal de Justiça do Distrito Federal e Territórios. Juíza mantém preço diferenciado de ingresso, mas aponta ilegalidade na forma de cobrança. Brasília: TJDFT; 2017 [citado 21 Mar 2019]. Disponível em: https://www.tjdft.jus.br/institucional/imprensa/ noticias/2017/junho/juiza-do-tjdft-aponta-ilegalidade-em-cobranca-de-ingressosdiferenciada-entre-homens-e-mulheres

32. Pinsky I, Noto AR, Botequio de Moraes MC, Lucas dos Santos E, Sparks R, O’Brien $\mathrm{K}$. Alcohol industry sponsorship of university student sports clubs in Brazil. J Stud Alcohol Drugs. 2017; 78(2):306-12.

33. São Paulo. Lei no 14.592. Proíbe vender, ofertar, fornecer, entregar e permitir o consumo de bebida alcoólica, ainda que gratuitamente, aos menores de 18 (dezoito) anos de idade, e dá providências correlatas. Diário Oficial - Executivo. 20 Out 2011.

34. Brasil. Lei no 13.106. Altera a Lei no 8.069, de 13 de Julho de 1990. Estatuto da Criança e do Adolescente, para tornar crime vender, fornecer, servir, ministrar ou entregar bebida alcoólica a criança ou a adolescente; e revoga o inciso I do art. 63 do Decreto-Lei no 3.688, de 3 de Outubro de 1941 - Lei das Contravençôes Penais. Diário Oficial da União. 17 Mar 2015.

35. Lena JC, Peterson RA. Classification as culture: types and trajectories of music genres. Am Sociol Rev. 2008; 73:697-718.

36. Ferreira PP. Transe maquínico: quando som e movimento se encontram na música eletrônica de pista. Horiz Antropol. 2008; 14(29):189-215.

37. Battisti MC, Noto AR, Carlini SNEA. A profile of ecstasy (MDMA) use in Sāo Paulo, Brazil: an ethnographic study. J Psychoactive Drugs. 2006; 38(1):13-8.

38. Muniz BB. Quem precisa de cultura? O capital existencial do funk e a conveniência da cultura. Sociol Antropol. 2016; 6(2):447-67.

39. Ilari B. Música, comportamento social e relações interpessoais. Psicol Estud. 2007; 11(1):191-8.

40. Wazlawick P, Camargo D, Maheirie I. Significados e sentidos da música: uma breve "composição" a partir da psicologia histórico-cultural. Psicol Estud. 2007; 12(1):105-

13. 
This study interpreted the images of parties advertisements distributed on a university campus in relation to student drinking. A semiotic image analysis was conducted of the plastic, iconic, and linguistic elements of the advertisements. Eighty-five themes were organized into six categories: alcoholic drinks, sexuality, gender, party production, musical styles, and lifestyle-groups-behavior. The advertisement encompassed various festive motives, attractions, gender issues, values, traditions, and economic purposes. The mention of alcoholic drinks was practically ubiquitous. Various persuasive elements were used to promote alcohol consumption involving the association between alcohol and sexuality and the presentation of new drink-linked behaviors and lifestyles. The alcohol industry was shown to have a strong informal presence on-campus, almost always failing to comply with legislation governing alcohol advertizing.

Keywords: Alcoholic drinks. Student health. Advertizing. Student parties. Advertisements.

El objetivo fue interpretar las imágenes de anuncios de fiestas exhibidas en un campus universitario con relación al consumo de alcohol por parte de los estudiantes. Los elementos plásticos, icónicos y lingüísticos de las propagandas se sometieron a un análisis semiótico de imágenes. Se organizaron los ochenta y cinco temas examinados en seis categorías: bebidas alcohólicas, sexualidad, género, producción de las fiestas, estilos musicales y estilo de vida-grupos-comportamiento. Se exhibieron motivaciones festivas, atracciones, cuestiones de género, valores, tradiciones y finalidades económicas. Las menciones a bebidas alcohólicas fueron prácticamente ubicuas. Los elementos persuasivos para el consumo de alcohol fueron variados, envolviendo la asociación alcoholsexualidad y la presentación de nuevos comportamientos y estilos de vida relacionados con la bebida. La industria de producción y comercio de bebidas parece inserirse mercadológicamente en el territorio del campus de manera informal y casi siempre sin seguir la legislación del marketing de estos productos.

Palabras clave: Bebidas alcohólicas. Salud del estudiante. Marketing. Fiestas estudiantiles. Anuncios. 